\title{
Adolescent Problem Video Gaming in Urban and Non-urban Regions
}

\author{
Jing Shi ${ }^{1,2}$ (D) Angela Boak $^{2} \cdot$ Robert Mann $^{2,3}$ • \\ Nigel E. Turner ${ }^{2,3}$
}

Published online: 17 January 2018

(C) The Author(s) 2018. This article is an open access publication

\begin{abstract}
The purpose of this paper is to explore the differences in adolescent problem video gaming in a large urban area (Toronto) compared to a non-urban region of Ontario (Northern Ontario). The results of this study showed that $76.6 \%$ of adolescents in the urban region and $80.3 \%$ of adolescents in the non-urban region played video games in the past year $(n=2175)$. Adolescents in the urban region were significantly more likely than adolescents in the non-urban region to experience problem video gaming (16.7 and 8.8\%, respectively). Males and those reporting poorer mental health were more likely to experience problem video gaming. Those who engaged in delinquent behaviors were more likely to experience problem video gaming in both regions, while problem gamblers were more likely to experience problem gaming in urban regions. Lower scholastic achievement was correlated with problem video gaming in the non-urban region.
\end{abstract}

Keywords Problem video gaming · Adolescents · Addiction · Youth · Correlates · Internet gaming disorder

Video gaming was first developed in the 1970s. Originally available mostly in arcades, video games are now available on computers, gaming consoles, smart phones, and tablets. Games can be played as single player games, with friends in multiplayer mode, or over the Internet with an unlimited number of participants. Video games are assumed to be safe and do not come with warning about the potential for addiction (Clark and Scott 2009). Physically, these games are safe for the most part, though repetitive strain injuries have been reported

Jing Shi

j.shi@mail.utoronto.ca

1 Rehabilitation Science Institute, University of Toronto, 937-500 University Ave, Toronto, ON M5G 1V7, Canada

2 Institute for Mental Health Policy Research, Centre for Addiction and Mental Health, Toronto, Canada

3 Dalla Lana School of Public Health, University of Toronto, Toronto, Canada 
(MacGregor 2000). However, the literature is pointing to the likelihood that some people can develop a video gaming problem (Hsu et al. 2009; ), which can lead to problems in other areas of life among adolescents (Hellstrom et al. 2012).

In the 1990s, "addiction" and "gaming problem" began to appear in the literature to describe those who spent excessive amounts of time online that interfered with other life activities (Chakraborty et al. 2010). Video game products are now a mature market, but the games are still changing at a remarkable pace as technology develops. The potential physical and psychosocial effects of video gaming are still not completely understood (Sublette and Mullan 2012). This is a new field of research, without a gold standard measure and little consensus on terminology (Carbonell et al. 2009). Excessive use of video games disrupts social lives, adversely affects health, and causes occupational disruptions. In extreme cases, a gamer might neglect essential activities in daily life such as eating and/or sleeping with fatal results (Christakis and Moreno 2009). The American Psychiatric Association (APA) introduced "Internet gaming disorder" (IGD) as an area requiring further research (2013). IGD is the "persistent and recurrent engagement in video games, often with other players, leading to clinically significant impairments or distress as indicated by five (or more) of" nine criteria within 12 months (APA 2013, p.795). In this paper, we will use the term problem video gaming.

The positive aspects to video gaming may be more prominent than those of other potentially addictive behaviors such as drinking, drug use, and gambling. For example, video games can improve visual-spatial cognition (Ferguson 2007) and can help with training surgeons in the use of modern surgical techniques (Rosser et al. 2007). Additionally, video gaming may direct some youth toward careers in technology (Ashford 2014). Several studies have discussed the social aspects of playing video games. Many adolescents are motivated to play video games because they can spend time with friends (Hellstrom et al. 2012) or make friends online through the games (Cole and Griffiths 2007).

With online games specifically, the social aspect where players can connect with each other online can render the activities more enticing, and possibly more problematic than many other Internet functions on the computer (van Rooij et al. 2010). The Internet is more accessible and found at faster speeds in urban regions compared to non-urban regions. It is likely that urban regions have a higher density of computers and video gaming platforms as well as higher income levels to support purchasing of games and compatible hardware/software. Furthermore, a study of Internet addiction found youth in urban regions are generally more at risk for an internet addiction compared to youth in rural regions (Stavropoulos et al. 2013).

In studies of other types of problem behaviors and addictions, youth and young adults in urban areas were more aware of the existence of psychoactive substances and used them more compared to those in rural areas (Martinotti et al. 2015; Pawlowska et al. 2014). Adolescents in urban areas also had higher habitual consumption of alcohol and binge drinking behaviors (Martinotti et al. 2015). Rural communities may be in isolation and poverty (Khan et al. 2002) and have less available and accessible prevention/treatment resources (Martinotti et al. 2015). Little research has been done on comparing problem video gaming between urban and rural regions. As a result, the area of policy decisions and intervention targets for problem video gaming has been underdeveloped.

This paper is exploratory in nature. This paper seeks to understand problem gaming among adolescents, its prevalence, and correlated factors while comparing an urban area with the northern non-urban area in Ontario. The following research questions are addressed: (1) 
Within the adolescent gamer population, what is the prevalence of problem video gaming in urban compared to non-urban regions?, (2) Is problem video gaming correlated with demographics and mental health status in urban compared to non-urban regions?, and (3) Is problem video gaming correlated with delinquency, gambling or scholastic achievement in urban and non-urban regions?

\section{Methods}

This study is a secondary analysis of the 2011 Ontario Student Drug Use and Health Survey (OSDUHS), a school-based survey that has been collected by the Centre for Addiction and Mental Health (CAMH). The survey uses a regionally stratified, two-stage cluster (school and class) design. The overall response rates for students was $63 \%$. The full sample of students who completed the questions on video game use was 4746 . The students ranged from grades 7 to 12. The four regions in the survey are Toronto, Northern Ontario, Western Ontario, and Eastern Ontario.

This paper focused on a contrast between two regions-Toronto and Northern Ontario. These regions were chosen because of the geographical contrast. Toronto is Canada's largest city while most of Northern Ontario consists of smaller towns scattered over a large area. Although there are a few small cities in Northern Ontario such as Thunder Bay, the population and population density of these Northern cities are much lower than that of Toronto. In this way, this paper compares a large urban city (Toronto) with a non-urban region (Northern Ontario) in Ontario.

The study included data from 1616 students of which 610 were from the urban region and 1006 were from the non-urban region. The initial video game question determined the frequency of playing in the past 12 months: "never played video games in a lifetime," "did not play in the last 12 months," "every day or almost every day," "4 or 5 times a week," "2 or 3 times a week," "once a week," "2 or 3 times a month," or "once a month or less often." A series of exclusion criteria were used to enhance data quality, minimize respondent bias, and retain only active gamers who had played within the last 12 months. Respondents were excluded if they had never played video games or had not played video games in the last 12 months. In total, 341 cases were excluded, resulting in a final sample of 1275 students (467 from the urban region and 808 from the non-urban region).

\section{Measures}

\section{Problem Video Game Playing Scale}

There is currently no accepted standard for the measurement of problematic video gaming. However, the Problem Video Game Playing Scale (PVP) is currently the most widely used tool in academic publications. The PVP has an acceptable internal consistency and item scores are reliable and valid (Tejeiro Salguero and Moran 2002). Although the PVP was originally developed with adolescents in Spain, the scale was found to be reliable with Ontario adolescents (Turner et al. 2012). This study uses a cut-off score of five or more out of nine items as previous research has used this score to determine the prevalence of problematic video gaming (Bioulac et al. 2008; Turner et al. 2012). Demographic variables included in this study were region, gender, and grade. 


\section{Mental Health Status}

Mental health status was obtained from the 12-item General Health Questionnaire (GHQ12). This instrument was designed to assess overall psychological well-being (Goldberg and Williams 1988) and has been validated among adolescents (Paglia-Boak et al. 2012). The items are added together to produce a range from 0 to 12 The higher the score on the GHQ12 indicates more symptoms of anxiety and depression.

\section{Delinquency, Gambling, and Scholastic Achievement}

There were 12 questions on delinquent behaviors (e.g., theft, vandalism, assault, drug selling) within the past 12 months. A score of 3 or more out of 12 was considered to demonstrate significant delinquency (Cook et al. 2015). The six questions measuring a potential gambling problem were taken from the South Oaks Screen Revised for Adolescents (SOGSRA) (Winters et al. 1993). Adolescents scoring two or more out of the six items were classified as having a gambling problem (Cook et al. 2015). Finally, scholastic achievement was measured by a self-reported response to the question, "On average, what marks do you usually get in school?," with the following options: 90-100\%, 80-89\%, 70-79\%, 60-69\%, 50-59\%, or below $50 \%$. For this exploratory study, delinquency, gambling problem, and scholastic achievement were used as continuous variables.

\section{Results}

Table 1 presents the demographic characteristics of the sample. The urban region had 467 (or $76.6 \%$ ) adolescent gamers and the non-urban region had 808 (or 80.3\%) adolescent gamers who played within the past year. The difference between the proportion of gamers in the two regions was not significant, chi-square $=3.2, p=.07$. An exploration of the data showed no duplicate data and no unusual cases. There was one missing value for the variable grade and 18 missing values for GHQ12 scores. These missing 19 cases accounted for $1.5 \%$ of the total sample. All tests were run with $95 \%$ confidence intervals and significance levels of $p=.05$.

For all male gamers in both regions, 115 out of 670 gamers scored in the problem range $(17.2 \%)$. For all female gamers in both regions, 34 out of 605 gamers were problematic gamers (5.6\%) (see Table 2). The modal age of adolescents who played video games within the past year was 15 years. There were no clear patterns in the histogram when looking at the grade levels of gamers and those who experienced problematic gaming. However, cross tabulations indicated that grade 10 had the most number of problematic gamers $(n=30)$ followed by grade $12(n=29)$. Grade $7(n=18)$ had the lowest number of problematic gamers. See percentage of problem gamers by grade in Table 3 .

The continuous variable GHQ12 was explored, and it is important to note that this variable was not normally distributed. The mean was much closer to the maximum than to the minimal value. The ratio of skewness by its standard error was greater than two. Skewness $=8.58$ and kurtosis was also greater than 2 at 4.59 . Therefore, the mean of 11.73 and standard deviation of 6.49 were not good measures of central tendency and variability for the GHQ12. This skew closer to the maximum value indicates our sample generally had good overall psychological well-being. Therefore, results using the GHQ12 measure should be interpreted with caution. 
Table 1 Demographics characteristics of the sample

\begin{tabular}{llll}
\hline & Toronto & North Ontario & Total \\
\hline Sample size & 610 & 1006 & 1616 \\
Video gamers (past year) & 467 & 808 & 1275 \\
Video gamers (\%) & $76.6 \%$ & $80.3 \%$ & $18.9 \%$ \\
GHQ12 score? & $11.7(\mathrm{SD}=6.5)$ & $10.6(\mathrm{SD}=6.0)$ & $11.0(\mathrm{SD}=6.2)$ \\
Male \% & $50.1 \%$ & $54.0 \%$ & $52.5 \%$ \\
Delinquency score? & $0.84(\mathrm{SD}=1.65)$ & $0.89(\mathrm{SD}=1.69)$ & $0.88(\mathrm{SD}=1.68)$ \\
Delinquency 3+(\%) & $10.7 \%$ & $11.8 \%$ & $11.4 \%$ \\
Gambling problems & $0.10(\mathrm{SD}=.47)$ & $0.09(\mathrm{SD}=.44)$ & $0.09(\mathrm{SD}=.45)$ \\
Gambling problems 2+(\%) & $1.8 \%$ & $1.7 \%$ & $1.8 \%$ \\
Scholastic achievement (A or higher, $\%)$ & $51.0 \%$ & $56.1 \%$ & $54.2 \%$ \\
Grade level & & & $18 \%$ \\
7 & $16.7 \%$ & $18.6 \%$ & $16.8 \%$ \\
8 & $14.8 \%$ & $17.9 \%$ & $18 \%$ \\
9 & $19.7 \%$ & $17 \%$ & $17.9 \%$ \\
10 & $16.3 \%$ & $18.8 \%$ & $14.2 \%$ \\
11 & $18.6 \%$ & $11.6 \%$ & $15.2 \%$ \\
12 & $13.9 \%$ & $16 \%$ & \\
\hline
\end{tabular}

All demographics are based only on video gamers who played within the last 12 months except for line 1

In the introduction, three questions that guided the analysis were stated. The first question was "Within the population of adolescent gamers, what is the prevalence of problem gaming in the urban compared to non-urban regions?" To address this research question and the next two research questions, the data needed to by split by region. In the urban region (Toronto), there were 467 gamers, and of those, 16.7\% met the criteria for problem use. In the non-urban region (Northern Ontario), there were 808 gamers, and of those, $8.8 \%$ met the criteria for problem use. The percentage of problem gamers in the urban region was significantly different from the non-urban region; the proportion of problem gamers in the urban region was almost double than that of the non-urban region $(16.7$ vs. $8.8 \%), X^{2}(1, N=1275)=17.97, p<.001$.

The second question was "Is problem video gaming correlated with demographics (sex and grade) and mental health status (GHQ12) in urban compared to non-urban regions?" A logistic

Table 2 Distribution of the PVP score by sex

\begin{tabular}{llll}
\hline PVP score & $\begin{array}{l}\text { Male } \\
(N=670)\end{array}$ & $\begin{array}{l}\text { Female } \\
(N=605)\end{array}$ & $\begin{array}{l}\text { Total } \\
(N=1275)\end{array}$ \\
\hline 0 & $23.9 \%$ & $44.3 \%$ & $33.6 \%$ \\
1 & $19.3 \%$ & $26.3 \%$ & $22.6 \%$ \\
2 & $15.8 \%$ & $11.4 \%$ & $13.7 \%$ \\
3 & $14.9 \%$ & $7.9 \%$ & $11.6 \%$ \\
4 & $9.0 \%$ & $4.5 \%$ & $6.8 \%$ \\
5 & & & \\
6 & $6.6 \%$ & $2.5 \%$ & $4.6 \%$ \\
7 & $4.6 \%$ & $1.8 \%$ & $3.3 \%$ \\
8 & $3.6 \%$ & $0.8 \%$ & $2.3 \%$ \\
9 & $1.3 \%$ & $0.5 \%$ & $0.9 \%$ \\
\hline
\end{tabular}

Scores 5 or higher on the PVP scale indicate problem video gaming 
Table 3 Percentage of problem video gamers by grade

\begin{tabular}{llll}
\hline Grade & $\begin{array}{l}\text { Toronto } \\
(N=467)\end{array}$ & $\begin{array}{l}\text { North } \\
(N=808)\end{array}$ & $\begin{array}{l}\text { Total } \\
(N=1275)\end{array}$ \\
\hline 7 & $11.5 \%$ & $6.0 \%$ & $7.9 \%$ \\
8 & $18.8 \%$ & $9.7 \%$ & $12.6 \%$ \\
9 & $14.1 \%$ & $8.8 \%$ & $10.9 \%$ \\
10 & $23.7 \%$ & $9.2 \%$ & $14.0 \%$ \\
11 & $13.8 \%$ & $9.6 \%$ & $11.6 \%$ \\
12 & $20.0 \%$ & $10.1 \%$ & $13.4 \%$ \\
Total & $16.7 \%$ & $8.8 \%$ & $11.7 \%$ \\
\hline
\end{tabular}

There were no clear patterns when looking at problem gamers by grade

regression analysis was conducted. The model had good fit $X^{2}(8)=130.98, p<.001$. However, the predictive power of the model, as measured by Nagelkerke R Square, was .19. This is not an unusual result given that most adolescent gamers were likely to not experience problem gaming; in other words, the occurrence of problem gaming was relatively low in this study. Males were about six times more likely to experience problem gaming $(\operatorname{Exp}(B)=6.27, p$ $<$.001) compared to females. Mental health status was also significantly related to problem gaming: those who scored 1 point higher on the GHQ12 indicating more mental health problems were 1.12 times more likely $(\operatorname{Exp}(B)=1.12, p<.001)$ to experience problem gaming. There was a significant main effect for region $(\operatorname{Exp}(B)=.448, p<.001$, showing that there were fewer problem gamers in the non-urban region compared to the urban region. There were no significant interactions between the GHQ12, sex, or grade by region.

The third question was whether problem video gaming is correlated with delinquency, gambling, and scholastic achievement in urban and non-urban regions? The results are shown in Table 4. The correlation between delinquency and problem gaming in the urban region was Spearman's rho $=.25, p<.001$; the correlation in the non-urban region was Spearman's rho $=$ $.23, p<.001$. However, the results for gambling and scholastic achievement were mixed. Problem gambling and gaming are positively correlated in the urban region according to Spearman's rho, where people who scored higher on problem gambling also scored higher on the PVP, Spearman's rho $=.20 . p<.001$. Problem gambling and gaming were found to not be correlated in the non-urban region according to Spearman's rho $=.07, p=.06$. There was no such relationship found among adolescents in the non-urban region. Finally, scholastic achievement and problem gaming were negatively correlated in the non-urban region, rho = $-.10, p<.01$. However, they were not related in the urban region.

Table 4 Comparison of Rho correlations of PVP scores

\begin{tabular}{llllll}
\hline & $N$ & Delinquency & Gambling & $\begin{array}{l}\text { Scholastic } \\
\text { achievement }\end{array}$ \\
\hline \multirow{2}{*}{ PVP scores } & Urban (Toronto) & 467 & $.25 * * *$ & $.20^{* * *}$ & .00 \\
& Non-urban (Northern Ontario) & 808 & $.23 * * *$ & .07 & $-.10^{* * *}$ \\
\hline
\end{tabular}

Comparison of Rho correlations of PVP scores with delinquency, problem gambling, and scholastic achievement among students in urban and non-urban regions in Ontario

$* * * p<.001 ; * * p<.01 ; * p<.05$ 


\section{Discussion}

\section{Implications and Future Directions}

This study found that adolescents who lived in a large urban region were twice as likely as those who lived in a non-urban region to experience problem gaming. Other researchers also speculated that smaller communities have stronger social cohesion and therefore greater opportunities for socialization and a higher sense of belonging than urban areas. These factors would protect adolescents from abusing the Internet (Stavropoulos et al. 2013) or video games. Furthermore, adolescents in urban areas showed significantly greater problematic Internet and computer use compared to those living in rural areas (Pawlowska et al. 2015). Therefore, urban areas have been recommended as a target for preventative strategies (Martinotti et al. 2015).This finding is helpful for policy makers to determine in which region funding should be directed when tackling the issue of problematic video gaming. This finding also raises many questions. What are the key factors (structural, environmental, lifestyle, etc.) in these areas that contribute to the difference between urban and non-urban areas? More research on the regional dispersion of adolescents who play video games and the supports available to them are needed.

The results showed a significantly higher proportion of adolescent problem gamers in the urban region than the non-urban region of Ontario (16.7 vs. 8.8\%, respectively). This suggests that adolescents in urban regions are more likely than adolescents in non-urban regions to be problem gamers. The World Internet Project 2012 and 2013 found that Sweden, the USA, and the UK had the highest levels of Internet usage at 86,85 , and $71 \%$, respectively. These three are all developed countries which tend to have high Internet usage and advanced technology that is well integrated into society compared to underdeveloped countries. This could be related to the frequency, duration, and speed of Internet access. Similarly, with urban and non-urban regions, if any of the three aspects of Internet access were limited, there could be a decrease in the chances of problem video gaming because the gamer could not play as frequently, could not play as long, and would experience in-game lag time while playing. Urban areas such as Toronto could be more likely to be on a high-speed internet network, with multiple internet cafes, gaming centers, and opportunities for LAN-parties (Local Area Network-parties).

Adolescents who were males or who had worse mental health status were significantly more likely to be problem gamers, while grade was not a significant predictor of problem gaming. That is, students across the six grades in the study sample (grades 7-12) were equally likely to experience problem video gaming. The findings of this study were consistent with others showing that males have higher problem video gaming scores than females (Ko et al. 2005; Turner et al. 2012; Yee 2006b). In contrast, some studies did not find a significant difference between males and females (Hsu et al. 2009; Li et al. 2011). While the vast majority (over 90\%) of gamers under 18 tend to be male (Griffiths et al. 2004; Yee 2006a), this trend is changing, in that more females are now playing video games. These inconsistent findings in the literature point to a need for further exploration in the future to develop theories on problem video gaming. This study sampled a large and almost equal number of male $(n=670)$ and female gamers $(n=605)$ whereas some previous studies in the literature included exclusively male participants or very few female participants (Lim \& Meier 2011). Studies in the future should continue to examine gender using equal samples of males and females.

Consistent with previous research, this study also showed that those with poor mental health status were likely to be problem gamers. An online survey found $19.4 \%$ of male gamers 
and $36.5 \%$ of female gamers had been diagnosed with depression (Williams et al. 2008). Many adolescents were found to use gaming as a form of escape from stress (Yee 2006a). As much as $23 \%$ of gamers were found to be depressed (Williams et al. 2008), and adolescents who played games had poorer psychological well-being than those who did not play (Devine and Lloyd 2012). Furthermore, depression, anxiety, and social phobias were consequences of problem video gaming in youth (Gentile et al. 2011). The results of the current study add strength to the literature and suggest a link between mental health distress problem gaming.

Adolescents who reported delinquent behaviors in the past year were more likely to experience problem video gaming in both regions. Other studies have noted that delinquency is positively correlated with video game playing, particularly violent video games (Anderson \& Dill 2000; Anderson 2004). Furthermore, Gupta and Derevensky (1996) also found that those who played video games more often also gambled more than those who played less video games. Adolescents in the urban region who were problem gamblers were more likely to be problem video gamers compared to adolescents who did not gamble. However, this association was not found in the non-urban region. This difference might be due to the lower saturation of casinos in the non-urban region. Findings from this study showing students with low scholastic achievement had a higher likelihood of experiencing problem video gaming is consistent with previous research. Past research found that gamers tended to neglect school, skip school, or skip sleep to game instead (Hellstrom et al. 2012). Schmitt and Livingston (2015) found problem video gaming to be negatively correlated with school engagement and college grades. However, the association found in this study pertained only to students in the non-urban region and not in the urban region. The differences between urban and non-urban regions for problem gambling and self-reported scholastic achievement are areas for further research.

The video game industry currently does not have regulations for gameplay, except for age requirements for games with explicit content. Prevention is the best method in tackling problem video gaming (Karapetsas et al. 2014). Currently, the only warning on video game products are for repetitive strain injuries and for game content (e.g., sexually explicit images and violence). The video game industry could consider presenting cautionary warning labels about the risk of psychological and social problems that can result from excessive gaming including the potential for an addiction. Furthermore, based on the results of this analysis, parents, teachers, and caregivers should beware that people who are under mental health distress may be more at risk for problem gaming. Prevention methods could involve informing, educating, and suggesting alternative activities (Doğan 2014). Adolescents who are male or have poor mental health status can be taught coping mechanisms in advance or have more supervisory monitoring on them when engaging in video game play (Doğan 2014).

The difference between the number of adolescent gamers in urban and non-urban regions is worthy of future research. More research is needed to examine the difference between nonurban and urban regions and their strongest predictors of problematic gaming to better tailor prevention and treatment interventions. There needs to be further exploration of different variables of problematic video gaming for health care professionals to adequately address significant risk factors. Other predictor variables to be explored could be those relating to substance abuse and other behavioral disorders. The current lack of solid theoretical guidance requires future researchers to compare gamers to non-gamers to advance the knowledge on video gamers in general. This calls for more qualitative research to build a stronger theoretical framework for problem video gaming research. 


\section{Limitations}

The main limitation of this paper includes the fact that there is no gold standard in measuring problem video gaming, and the results of the analyses are based on cut-off scores from the PVP as determined by previous literature. There are also limitations in the use of survey methods research where there is a risk of self-report bias, social desirability bias (Fisher 1993), and errors in retrospective responses (Bernard et al. 1984). Adolescents in this study may have under-reported items that determine problem gaming on the PVP and/or under-reported items that determine mental health status on the GHQ12. These factors would have contributed to limitations in interpreting the results of the analyses.

\section{Conclusions}

This study addressed questions relating to the prevalence of problem video gaming among adolescents in urban and non-urban regions. Adolescents in the urban region were significantly more likely to be problem video gamers than adolescents in the non-urban region. It also contributed to theory development by finding four significant predictors - decreased mental health status, male gender, delinquency, and problem gambling —of problem video gaming in urban regions. As well, there were four significant predictors - decreased mental health status, male gender, delinquency, and scholastic achievement - in non-urban regions. These findings can help inform choices made by caregivers, health care professionals, and policy makers.

Acknowledgements The authors would like to acknowledge the staff and researchers at CAMH who were involved in the creation and data collection of the OSDUHS. We would also like to thank the Institute for Social Research at York University, who administered the survey on behalf of CAMH. Finally, we would like to recognize Peter Ferentzy and Christopher Pak for providing valuable input in the editing the manuscript.

Funding Partial funding for this project was from the Ministry of Health and Long Term Care, grant \#425 (2017).

\section{Compliance with Ethical Standards}

Conflict of Interest The authors declare that they have no conflicts of interest.

Informed Consent This study was a secondary analysis of a publicly available dataset; however, all procedures followed were in accordance with the ethical standards of the responsible committee on human experimentation (institutional and national) and with the Helsinki Declaration of 1975, as revised in 2000 (5). Informed consent was obtained from all respondents at the beginning of the survey. The protocol was reviewed and approved by the Research Ethics Board of the Centre for Addiction and Mental Health as protocol no. 305/2009-4.

Open Access This article is distributed under the terms of the Creative Commons Attribution 4.0 International License (http://creativecommons.org/licenses/by/4.0/), which permits unrestricted use, distribution, and reproduction in any medium, provided you give appropriate credit to the original author(s) and the source, provide a link to the Creative Commons license, and indicate if changes were made.

\section{References}

American Psychiatric Association. (2013). Diagnostic and statistical manual of mental disorders (5th ed.). Arlington, VA: American Psychiatric Publishing. 
Anderson, C. A. (2004). An update on the effects of playing violent video games. Journal of Adolescence, 27, 113-122.

Anderson, C. A., \& Dill, K. E. (2000). Video games and aggressive thoughts, feelings, and behavior in the laboratory and in life. Journal of Personality and Social Psychology, 78, 772-790.

Ashford, E., (2014). Gamers grow up into developers. Community College Daily. Retrieved fromhttp://www. ccdaily.com/pages/technology/gamers.aspx.

Bernard, H. R., Killworth, P., Kronenfeld, D., \& Sailer, L. (1984). The problem of informant accuracy: the validity of retrospective data. Annual Review of Anthropology, 13(1), 495-517.

Bioulac, S., Arfi, L., \& Bouvard, M. P. (2008). Attention deficit/hyperactivitiy disorder and video games: a comparative study of hyperactive and control children. European Psychiatry, 23, 134-141.

Carbonell, X., Guardiola, E., Beranuy, M., \& Belles, A. (2009). A bibliometric analysis of the scientific literature on Internet, video games, and cell phone addiction. Journal of the Medical Library Association, 97(2), 102107.

Chakraborty, K., Basu, D., \& Vijaya Kumar, K. G. (2010). Internet addiction: consensus, controversies, and the way ahead. East Asian Archives in Psychiatry, 20(3), 123-132.

Christakis, D. A., \& Moreno, M. A. (2009). Trapped in the net. Will internet addiction become a 21st-century epidemic? Archives of Paediatric \& Adolescence Medicine, 163, 959-960.

Clark, N., \& Scott, P. S. (2009). Game addiction: the experience and the effects. Jefferson: North Carolina: McFarland \& Company, Inc., Publishers.

Cole, H., \& Griffiths, M. D. (2007). Social interactions in massively multiplayer online role-playing gamers. Cyberpsychology \& Behavior, 10(4), 575-583.

Cook, S., Turner, N. E., Ballon, B., Paglia-Boak, A., Murray, R., Adlaf, E. M., et al. (2015). Problem gambling among Ontario students: associations with substance abuse, mental health problems, suicide attempts, and delinquent behaviours. Journal of Gambling Studies, 31(4), 1121-1134.

Devine, P., \& Lloyd, K. (2012). Internet use and psychological well-being among 10-year-old and 11-year-old children. Child Care in Practice, 18(1), 5-22.

Doğan, A. (2014). Prevention and treatment of games addiction: non-pharacological approaches for game addiction. In S. Gunuc (Ed.), Epidemiology of game addicition Retreived from http://esciencecentral. org/ebooks/epidemiology/prevention-and-treatments-of-games-addiction-nonpharmacological-approachesfor-game-addiction.php.

Ferguson, C. J. (2007). The good, the bad and the ugly: a meta-analytic review of positive and negative effects of violent video games. Psychiatric Quarterly, 78(4), 309-316.

Fisher, R. (1993). Social desireability bias and the validity of indirect questioning. The Journal of Consumer Research, 20(20), 303-315.

Gentile, D. A., Choo, H., Liau, A., Sim, T., Fung, D., \& Khoo, A. (2011). Pathological video game use among youths: a two-year longitudinal study. Pediatrics, 127(2), 319-329.

Goldberg, D. P., \& Williams, P. (1988). A user's guide to the general health questionnaire. Windsor UK: NFERNelson.

Griffiths, M. D., Davies, M. N. O., \& Chappell, D. (2004). Online computer gaming: a comparison of adolescent and adult gamers. Journal of Adolescence, 27(1), 87-96.

Gupta, R., \& Derevensky, J. L. (1996). The relationships between gambling and video-game playing behavior in children and adolescents. Journal of Gambling Studies, 12(4), 375-394.

Hellstrom, C., Nilsson, K. W., Leppert, J., \& Aslund, C. (2012). Influences of motives to play and time spent gaming on the negative consequences of adolescent online computer gaming. Computers in Human Behavior, 28(4), 1379-1387.

Hsu, S. H., Wen, M.-H., \& Wu, M.-C. (2009). Exploring user experiences as predictors of MMORPG addiction. Computers \& Education, 53(3), 990-999.

Karapetsas, A. V., Karapetsas, V. A., Zygouris, N. X., \& Fotis, A. I. (2014). Internet gaming addiction. Reasons, diagnosis, prevention, and treatment. Encephalos, 51, 10-14.

Khan, S., Murray, R. P., \& Barnes, G. E. (2002). A structural equation model of the effect of poverty and unemployment on alcohol abuse. Addictive Behaviour, 27, 405-234.

Ko, C. H., Yen, Y. J., Chen, C. C., Chen, S. H., \& Yen, C. F. (2005). Gender differences and related factors affecting online gaming addiction among Taiwanese adolescents. The Journal of Nervous and Mental Disease, 193(4), 273-277.

Li, D., Liau, A., \& Khoo, A. (2011). Examining the influence of actual-ideal self-discrepancies, depression, and escapism, on pathological gaming among massively multiplayer online adolescent gamers. Cyberpsychology, Behavior and Social Networking, 14(9), 535-539.

Lim, K., \& Meier, E. B. (2011). Different but similar: computer use patterns between young Korean males and females. Educational Technology Research and Development, 59(4), 575-592. 
MacGregor, D. M. (2000). Nintendonitis? A case report of repetitive strain injury in a child as results of playing computer games. Scottish Medical Journal, 45(5), 150.

Martinotti, G., Lupi, M., Carlucci, L., Cinosi, E., Santacroce, R., Acciavatti, T.,. .. Di Giannantonio, M. (2015). Novel psychoactive substances: use and knowledge among adolescents and young adults in urban and rural areas. Human Psychopharmacology, 30(4), 295-301.

Paglia-Boak, A., Adlaf, E. M., Hamilton, H. A., Beitchman, J. H., Wolfe, D., \& Mann, R. E. (2012). Mental Health and Well-being of Ontario Students 1991-2011 (CAMH research document series no. 34). Toronto: Centre for Addiction and Mental Health.

Pawlowska, B., Zygo, M., Potembska, E., Kapka-Skrzypczak, L., Dreher, P., \& Kedzierski, Z. (2014). Psychoactive substances use experience and addiction or risk of addiction among by Polish adolescents living in rural and urban areas. Annals of Agricultural \& Environmental Medicine, 21(4), 776-782.

Pawlowska, B., Zygo, M., Potembska, E., Kapka-Skrzypczak, L., Dreher, P., \& Kedzierski, Z. (2015). Prevalence of Internet addiction and risk of developing addiction as exemplified by a group of Polish adolescents from urban and rural areas. Annals of Agricultural \& Environmental Medicine, 22(1), 129-136.

Rosser, J. C., Lynch, P. J., Cuddihy, L., Gentile, D. A., Klonsky, J., \& Merrell, R. (2007). The impact of video games on training surgeons in the 21st century. Archives of Surgery, 142(2), 181-186.

Schmitt, Z. L., \& Livingston, M. G. (2015). Problem video gaming and college performance among males: results from a 1year longitudinal study. Cyberpsychology, Behavior and Social Networking, 18(1), $25-29$.

Stavropoulos, V., Alexandraki, K., \& Motti-Stefanidi, F. (2013). Recognizing internet addiction: prevalence and relationship to academic achievement in adolescents enrolled in urban and rural Greek high schools. Journal of Adolescence, 36(3), 565-576.

Sublette, V. A., \& Mullan, B. (2012). Consequences of play: a systematic review of the effects of Online gaming. International Journal of Mental Health Addiction, 10(1), 3-23.

Tejeiro Salguero, R. A., \& Moran, R. M. (2002). Measuring problem video game playing in adolescents. Addiction, 97(12), 1601-1606.

Turner, N. E., Paglia-Boak, A., Ballon, B., Cheung, J. T. W., Adlaf, E. M., Henderson, J., et al. (2012). Prevalence of problematic video gaming among Ontario adolescents. International Journal of Mental Health and Addiction, 10(6), 877-889.

van Rooij, A. J., Schoenmakers, T. M., van de Eijnden, R. J., \& van de Mheen, D. (2010). Compulsive internet use: the role of online gaming and other Internet applications. Journal of Adolescent Health, 47(1), 51-57.

Williams, D., Yee, N., \& Caplan, S. E. (2008). Who plays, how much, and why? Debunking the stereotypical gamer profile. Journal of Computer-Mediated Communication, 13(4), 993-1018.

Winters, K. C., Stinchfield, R. D., \& Fulkerson, J. (1993). Toward the development of an adolescent gambling problem severity scale. Journal of Gambling Studies, 9(1), 63-84.

World Internet Project (2012). International Report (4th Ed.). Retrieved from http://www.worldinternetproject. net/files/_Published/_oldis/770_2012wip_report4th_ed.pdf

World Internet Project (2013). International Report (5th Ed.). Retrieved from http://www.worldinternetproject. net/files///307_2013worldinternetreport.pdf

Yee, N. (2006a). The demographics, motivations, and derived experiences of users of massively multi-user online graphical environments. Presence: Teleoperators and Virtual Environments, 15(3), 309-329.

Yee, N. (2006b). The motivations for play in online games. Cyberpsychology \& Behaviour, 9(6), 772-775. 